\title{
EVALUATION OF VISUAL ACUITY AND QUALITY OF LIFE AFTER CATARACT SURGERY IN KOLAR DISTRICT
}

K. Kanthamani ${ }^{1}$, Narendra P. Datti ${ }^{2}$, Prashanth $K^{3}$, Deepankar ${ }^{4}$, Nagesha C.K ${ }^{5}$

\section{HOW TO CITE THIS ARTICLE:}

K. Kanthamani, Narendra P. Datti, Prashanth K, Deepankar, Nagesha C.K."Evaluation of Visual Acuity and quality of life after Cataract Surgery in Kolar district". Journal of Evolution of Medical and Dental Sciences 2014; Vol. 3, Issue 02, January 13; Page: 495-500, DOI:10.14260/jemds/2014/1855

ABSTRACT:INTRODUCTION: Cataract is a highly treatable condition due to advances in cataract surgery procedures. The aim of cataract surgery is to improve visual function which in turn will improve overall quality of life. OBJECTIVE: To evaluate visual acuity and quality of life after cataract surgery. MATERIALS \& METHODS: Five hundred patients having senile cataract attending the outpatient department of ophthalmology at R.L.JALAPPA Hospital between January 2011 to March 2011 were included in the study. Cataract extraction was performed using manual small incision cataract surgery (SICS) and rigid PMMA posterior chamber intraocular lenses was implanted in all patients. Visual acuity - pre \& post operatively was recorded for every patient. The visual acuity was divided into grades for the purpose of statistical analysis. Quality of life was assessed by a questionnaire analyzing distant \& near vision, social functions and cataract related symptoms. Each item in the questionnaire was scored and total score was calculated for each patient and graded. RESULTS: After 6 weeks postoperatively, 455(91\%) subjects had BCVA of 6/18 or better, 39(7.8\%) had vision lesser than $6 / 18$ but better than $6 / 60$ and $6(1.3 \%)$ subjects had BCVA $6 / 60$ seller equivalent or worse. In this study pre-operative general function was $22.2 \pm 3.25$, social function was $5.68 \pm 1.07$ and visual function was $15.76 \pm 1.05$. Post operatively general function score was $53.05 \pm 11.59$, social functions was $13.35 \pm 3.07$ and visual function was $23.23 \pm 3.18$. Post-operative score was high resulting in significant improvement in quality of life $(p<0.001)$.CONCLUSION: Quality of life with respect to physical capability, social functions and mental health improved after cataract surgery.

KEYWORDS: Small incision cataract surgery, Quality of life, senile cataract, visual acuity.

INTRODUCTION: Cataract has been consistently documented to be the most common cause of blindness in developing countries. Cataract is the leading cause of blindness worldwide, accounting for nearly half of all cases of blindness. ${ }^{1}$ Of the estimated 38-45 million blind in the world (vision $<3 / 60$ in the better eye, with available correction), nearly one fifth live in India alone. ${ }^{2}$ Annual incidence of 3.8 million cataracts and over 9 million cataract blind people has been reported in India. ${ }^{3}$ Cataract is a highly treatable condition due to advances in cataract surgery, procedures and intraocular lens design. In developing countries surgery is generally performed when cataract affects patient's daily activities.

Manual small incision cataract surgery offers advantages with the merits of wider applicability, better safety, a shorter learning curve and lower cost. Visual impairment from cataract is associated with difficulties with activities of daily living and reduces quality of life. The aim of cataract surgery is to improve visual function which will also improve overall quality of life.

This study has been designed to assess visual status following cataract surgery and in turn reflect upon the improvement in quality of life. 
MATERIALS AND METHODS: Five hundred patients attending to outpatient department of ophthalmology, R.L.JALAPPA HOSPITAL attached to SRI DEVARAJ URS MEDICAL COLLEGE, TAMAKA, KOLAR with senile cataract fulfilling the inclusion criteria framed were selected for manual small incision cataract surgery under peribulbar anesthesia between January 2011 to May 2011.

Inclusion Criteria: Senile cataracts

Exclusion criteria: Subluxated lens

Lens induced glaucoma

Senile cataract with Pseudoexfoliation syndrome

Co-existing ocular pathology.

All patients fulfilling the above criteria were included in the study and admitted one day prior to surgery. Complete eye examination including snellen's visual acuity testing, slit lamp examination, direct and indirect ophthalmoscopy, intraocular pressure measurement by applanation tonometry and lacrimal syringing was done. Keratometry by Bausch \& Lomb keratometer, A-Scan biometry, IOL power calculation by SRK-2 formula was done. General physical and systemic examination including cardiovascular system and respiratory system examination, blood pressure recording and blood sugar estimation, serum urea, creatinine and ECG were done.B-Scan was done when posterior segment view was hindered by hazy media. Quality of life was assessed by a questionnaire (modified from Chan et al) preoperatively and at 3 months after surgery. The questionnaire consisted of 20 questions analyzing distant vision, near vision, social functions and cataract related symptoms.

Following Manual small incision cataract surgery with rigid intraocular lens implantation visual acuity testing (unaided \&best corrected visual acuity) was recorded for every patient on Day 1, Day 5, 2 weeks and 6 weeks post operatively. Slit lamp and fundus examination was done for all follow ups. Quality of life was again assessed 3 months post operatively.

The visual acuity was divided into the following grades for the purpose of statistical analysis. Grade 1 if visual acuity <6/60, Grade 2 for $6 / 60$ to $6 / 18$ and Grade 3 if VA $\geq 6 / 18$. Each item in the questionnaire was scored. That is, 2 points were given if the patient reported no symptoms, 1 point for moderately affected and 0 points if severely affected. For the purpose of statistical analysis total score was calculated for each patient and graded as not affected, slightly, moderately and severely affected with score 31-40, 21-30, 11-20 \& 0-10 respectively. Similarly quality of life was assessed in all these patients preoperatively and postoperatively by standard quality of life questionnaire modified from Chan et al. The scoring system and grading were done similar to that of visual scoring system with 0-2points and grade 1-4.

RESULTS: A total of 500 patients with cataract were enrolled in the study from January 2011 to May2011. The mean age group was 63.06+ 8.99 years (Range 40-85 years) with a female predominance 272(54.4\%) (Graph: 1).

Among 500 evaluated, 302 (60.4\%) had senile immature cataract, 195 (39\%) had mature cataract and 23cases were hypermature cataract. Preoperative biometry $(n=500)$ demonstrated a mean axial length of $23.13 \mathrm{~mm}$ and a mean keratometry of 43.69D. 
The maximum number of patients had vision of hand movement, counting finger and perception of light preoperatively. Post operatively the percentage of patients with BCVA of $6 / 6$ to $6 / 9$ on day one is $49 \%$, on first week it improved to $78 \%$ and on six weeks is $84.2 \%$ (Table: 1 ).

A total of $22 \%$ patients were having some early post-operative complications and in that strait keratopathy (8\%) was most commonly present followed by iritis (6\%) than hyphaema (5\%). Over next 4-6 weeks, iridocyclitis, hyphaema were completely resolved still $12 \%$ of patients were having complications resulting in less vision. Causes were posterior capsular opacity (4\%), Cystoid macular edema (3\%) followed by secondary glaucoma (2\%), striate keratopathy and corneal decompensation.

The pre and post-operativecomparative tables shows significant improvement in general functioning score $(\mathrm{p}<0.001)$, social functioning score $(\mathrm{p}<0.001)$, visual functioning score $(\mathrm{p}<0.001)$ post operatively. (Table 2, Graph: 2-4).

Quality of life preoperatively was severely affected in 312(69.3\%) patients, moderately affected in $100(22.2 \%)$ patients and slightly affected in 38(8.4\%) patients.

Postoperative quality of life was not affected in 342(76\%) patients, slightly affected in $50(11.1 \%)$ patients, moderately affected in $48(10.66 \%)$ patients and severely affected in $10(2.22 \%)$ patients. Quality of life with respect to physical capability, social functions and mental health improved after cataract surgery.

DISCUSSION: Cataract surgery can be considered successful if the operation restores the visual functioning and vision related quality of life in cataract patients to levels similar to that among unoperated individuals with similar vision status

In this study $91 \%$ number of patients had a visual acuity of $6 / 18$ or better. This correlates well with other studies. In the study done by Dandona L et al, 1390 patients underwent cataract surgery at Mudhol center and 954 patients underwent cataract surgery at Toodukurthy center. At Mudhol center $1213(87.30 \%)$ of patients have a visual acuity of $6 / 18$ or better and at Toodukurthy center $798(83.6 \%)$ of patients have a visual acuity of $6 / 18$ or better. ${ }^{4}$ In the study done by Bachani $D$ et al, 2369 patients underwent cataract surgery and $71.40 \%$ of patients have a visual acuity of $6 / 18$ or better. ${ }^{2}$ In the study done by Khan MT et al, 134 patients underwent cataract surgery and $86.80 \%$ of patients having a visual acuity of $6 / 18$ or better. 5 (Table3).

In our study complications encountered were accounted for nearly $9 \%$ subnormal visual acuity at the end of 6week follow-up. The complications were comparable in magnitude with previous studies by Khan M T et al, Rangaraj and coauthors and Riley A F et al. No significant morbidity occurred in our study like endophthalmitis.

In this study preoperative general functions were $22.2 \pm 3.25$, social functions were $5.68 \pm$ 1.07 and visual functions were $15.76 \pm 1.05$. Post operatively general function score were $53.05 \pm$ 11.59 , social functions were $13.35 \pm 3.07$ and visual function were $23.23 \pm 3.18$. As post-operative score was high shows significant improvement in quality of life post operatively $(\mathrm{p}<0.001)$. This correlates well with other studies.

In an another study done by Owsley $\mathrm{C}$ et al on the impact of cataract surgery on health related quality of life in nursing home residence reported significant score improvement in the general vision $(\mathrm{p}=0.005)$, reading $(\mathrm{p}=0.001)$, psychological distress and social interaction of the nursing home vision targeted health related quality of life questionnaire. ${ }^{6}$ 
Applegate W.B.14 et al in his study showed that maximum improvement in vision and improvements in subjective measures of patient function 69 occurred by 4 months and most improvement were maintained at 1 year. ${ }^{7}$

CONCLUSION: Patients who underwent cataract surgery reported improvements in their vision targeted health related quality of life, in addition to improvements in their vision They experienced improved general vision, fewer limitations because of vision, less difficulty with reading, less worry, frustration or upset over their vision, and greater ease and likelihood of engaging in social interactions.

\section{REFERENCES:}

1. Resnikoff S, Pascolini D, Etya'ale D, et al. Global data on visual impairment in the year 2002. Bull World Health Organ. 2004; 82: 844-851.

2. Bachani D, Gupta SK, Murthy GVS, Jose R. Visual outcomes after cataract surgery and cataract surgical coverage in India. Ophthalmology. 1999; 23, 49-56.

3. Minassian DC, Mehra V. 3.8 million blinded by cataract each year: Projections from the first epidemiological study of incidence of cataract blindness in India. Br JOphthalmoI1990; 74:3413.

4. Dandona L, Dandona $\mathrm{R}$, Anand Ret al. Outcome and number of cataract surgeries in India.Clinical and experimental ophthalmology 2003; 31:23-31.

5. Khan MT, Jan S, Hussain Z et al. Visual outcome and complications of manual sutureless small incision cataract surgery. Pak J Ophthalmic 2010; 32-38.

6. Owsley C, Me Gwin G Jr, Scilley K. Impact of cataract surgery on health relatedquality of life in nursing home residents. Br J Ophthalmol. 2007;91, 1359-1363.

7. Applegate WB, Miller ST, Elan JT, Freeman 1M, Wood TO et al. Impact of cataract surgery with lens implantation on vision and physical function in elderly patients. Jama. 1987;257, 10641066.

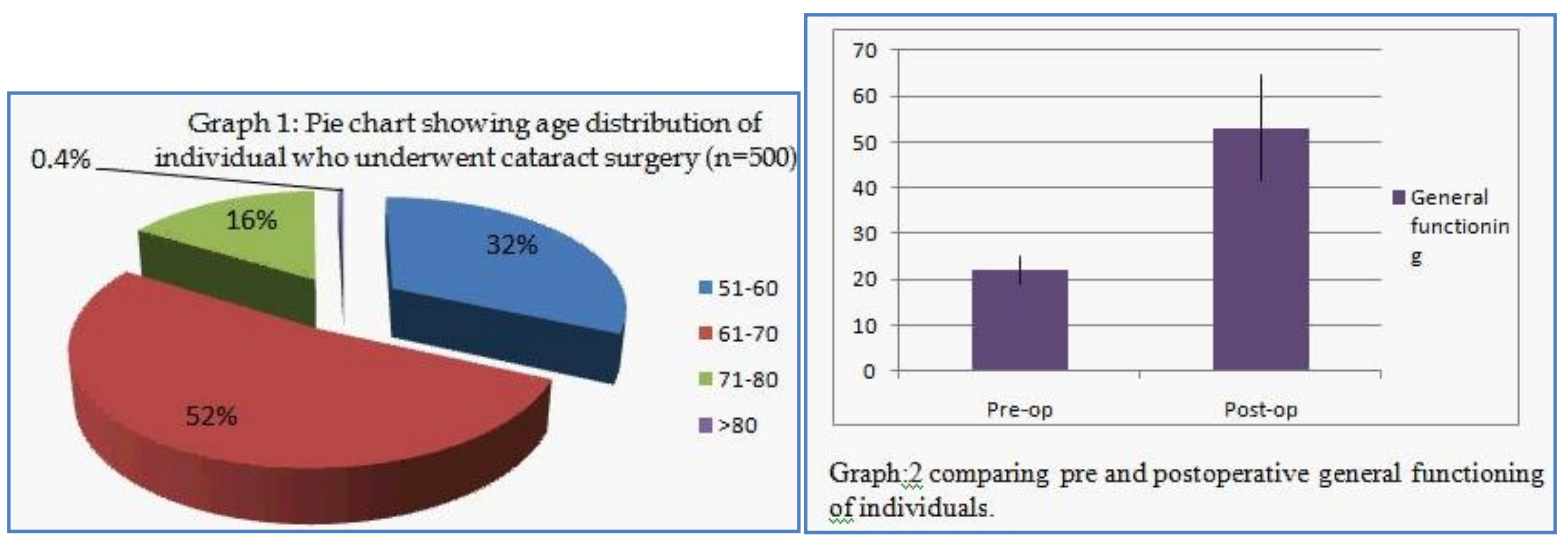



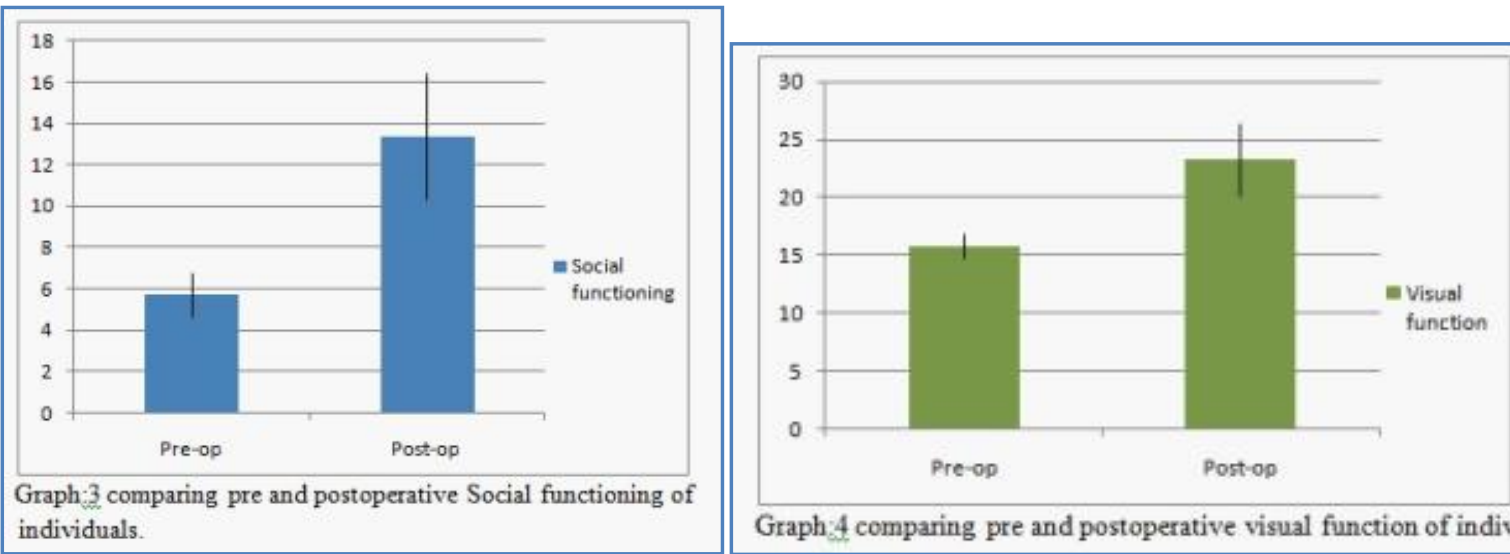

Graph 4 comparing pre and postoperative visual function of individuals.

\begin{tabular}{|c|c|c|c|c|c|}
\hline Visual acuity & Preop & Post-op day1 & $\begin{array}{c}\text { Post op } \\
\text { 1week }\end{array}$ & $\begin{array}{c}\text { Post op } \\
6 \text { weeks }\end{array}$ & $\%$ change \\
\hline $6 / 6-6 / 9$ & 0 & $245(49 \%)$ & $390(78 \%)$ & $421(84.2 \%)$ & $+84.2 \%$ \\
\hline $6 / 12-6 / 18$ & 0 & $111(22.2 \%)$ & $51(10.2 \%)$ & $34(6.8 \%)$ & $+6.8 \%$ \\
\hline $6 / 24-6 / 36$ & $15(3 \%)$ & $91(18.2 \%)$ & $38(7.6 \%)$ & $31(6.2 \%)$ & $+3.2 \%$ \\
\hline $6 / 60$ & $50(10 \%)$ & $29(5.8 \%)$ & $10(2 \%)$ & $8(1.6 \%)$ & $-8.4 \%$ \\
\hline HM/CF/PL & $435(87 \%)$ & $24(4.8 \%)$ & $11(2.2 \%)$ & $6(1.2 \%)$ & $-85.8 \%$ \\
\hline
\end{tabular}

Table1: Comparision of visual acuity before and after surgery on day 1, 1week and 1month $(\mathrm{n}=500)$

\begin{tabular}{|l|l|l|l|}
\hline Variables & Pre op score & Post op score & Significaance \\
\hline General functioning & $22.2+3.25$ & $53.05+11.59$ & $\mathrm{t}=56.482 ; \mathrm{p}<0.001$ \\
\hline Social functioning & $5.68+1.07$ & $13.35+3.07$ & $\mathrm{t}=53.054 \mathrm{p}<0.001$ \\
\hline Visual functioning & $15.76+1.05$ & $23.23+3.18$ & $\mathrm{t}=49.637 \mathrm{p}<0.001$ \\
\hline Total & $43.65+4.52$ & $89.22+17.2$ & $\mathrm{t}=56.511 ; \mathrm{p}<0.001$ \\
\hline
\end{tabular}

Table 2: Comparison of pre \& post operative general, social and visual functioning total scores $(n=500)$

\begin{tabular}{|c|c|c|c|}
\hline S1. No & Study & No. of patients operated & $\begin{array}{c}\text { Percentage of patients having } \\
\text { BCVA of 6/18 or better }\end{array}$ \\
\hline 1 & Our study & 500 & $91 \%$ \\
\hline 2 & Dandona L & $\begin{array}{c}1390 \text { (Mudhol center) } \\
954 \text { (Toodukurthy center) }\end{array}$ & $\begin{array}{c}87.3 \%(\text { Mudhol center) } \\
83.6 \% \text { (Toodukurthy center) }\end{array}$ \\
\hline 3 & Bachani D & 2369 & $71.40 \%$ \\
\hline 4 & Khan M T & 134 & $86.80 \%$ \\
\hline
\end{tabular}

Table3: Comparision of visual outcomes between the studies 


\section{ORIGINAL ARTICLE}

\section{AUTHORS:}

1. K. Kanthamani

2. Narendra P. Datti

3. Prashanth K.

4. Deepankar

5. Nagesha C.K.

\section{PARTICULARS OF CONTRIBUTORS:}

1. Professor, Department of Ophthalmology, SDUMC, Tamaka, Kolar.

2. Professor and HOD, Department of Ophthalmology, SDUMC, Tamaka, Kolar.

3. Associate Professor, Department of Ophthalmology, SDUMC, Tamaka, Kolar.
4. Junior Resident, Department of Ophthalmology, SDUMC, Tamaka, Kolar.

5. Assistant Professor, Department of Ophthalmology, SDUMC, Tamaka, Kolar.

\section{NAME ADDRESS EMAIL ID OF THE CORRESPONDING AUTHOR:}

Dr. K. Kanthamani.

Professor, Department of Ophthalmology, Sri Devaraj Urs Medical College, Tamaka, Kolar - 563101, Karnataka. Email-dr.kanthamanik@gmail.com

Date of Submission: 02/12/2013. Date of Peer Review: 04/12/2013. Date of Acceptance: 18/12/2013. Date of Publishing: 11/01/2014 